\title{
Inventory Valuation Practices and Reporting: Nigerian Textile Industry Experience
}

\author{
Onoja Emmanuel E, Ph.D \\ Department of Accounting, Kogi State University, Anyigba \\ Email: onojaandco@ymail.com \\ Yahya Uthman Abdullahi
}

Department of Accounting \&Finance, Northwest University, Kano

Doi:10.5901/mjss.2015.v6n4p74

\begin{abstract}
This study examined the inventory practice and reporting in the Nigeria textile industry in order to ascertain the superiority between first-in first-out (FIFO) and weighted-average-price (WAP) valuation methods. Inventory represents a large (if not largest) portion of assets in manufacturing firms that makes up an important part of the balance sheet. Valuation of inventories is as much a theoretical problem as a practical problem. In order for a valuation of inventory to be correct, the quantity on hand needs to be accurate. The FIFO and WAP inventory methods are commonly used including textile industry. Questionnaire was used in collecting data from the respondents. Descriptive method of statistical data analysis is used to analyze the data collected. The study revealed among others that FIFO method gives realistic cost of closing stock as such more superior to WAP method of stock valuation in Textile industry in Nigeria. Also FIFO method is simply to understand and apply than WAP method which is difficult to operate, hence it is superior to WAP and therefore preferred to other methods. Based on the findings the study recommends that for consistency and uniformity all firms within the Industry should value and report their inventory using FIFO method, and also for equity and fairness on tax issues to both the firms and the Government, FIFO method should be use for the Nigerian Textiles Industry, because it matches revenue against the initial cost of inventory and therefore, does not over-state or under-state profit of the firm.
\end{abstract}

Keywords: Textile, First- In- First- Out, Weighted-Average-Price, Industry

\section{Introduction}

The motives for keeping inventories differ among companies, depending on, if the inventory is designed for a process, for a flow of materials, or for a function it has to accomplish for a company (Friberg, Nilsson \& Warnbring, 2006). Inventory represents a large (if not largest) portion of assets of manufacturing firms and as such, makes up an important part of the balance sheet items. It is, therefore, crucial for investors who are analysing stocks to understand how inventory is valued (Investopedia, 2010). If materials are purchased exactly as required in production, the cost of a particular consignment could be immediately attributed to a specific job or production order. Frequently, however, materials are purchased in large quantities at different prices and issued to production in smaller lots. In attempting to establish costs of production, therefore, the cost accountant has the problem of identifying the material costs of each issue of stock from the stores to production department of other department (Adeniji, 2009).

In practice, prices fluctuate due to a number of reasons. Such reasons are: Inflation, changes in world commodity prices, buying from different sources, differences in quantity discounts, and others. It is clear that there may be a number of identical materials in the store bought at different prices. When one of these materials is issued, it is necessary to determine the price at which it should be charged (Investopedia, 2010).

According to ICAN (2009), there are many methods of pricing or valuing materials. The most popular methods are discussed in the Statement of Accounting Standards (SAS) No. 4, on Accounting for Stocks, issued by the Nigerian Accounting Standards Board (NASB). SAS 4 recommends Stocks valuation methods like First-In-First Out (FIFO); Weighted Average Price (WAP), Specific Identification (SI), Last-In-First-Out (LIFO), Standard Cost (SC), Based Stock (BS), Last Purchase Price (LPP) and Adjusted Selling Price (ASP) or Retail Inventory Method (RIM) for use by businesses.

The standard, however, lays more emphasis on three methods. These are: FIFO, LIFO, and WAP. In line with the Statement of Accounting Standards (SAS) No. 4, the selection of each of these methods is usually guided by the principle 
of matching of cost with revenue. In this study, efforts would be made to critically look at the various arguments on the superiority and relevance between FIFO and WAP inventory valuation method in the Nigerian textile industry.

\section{Statement of the Problem}

From a practical point of view, companies have to consider which costs need to be included in the pricing of materials when valuing inventories. It is important that companies, for financial reasons, are aware of all the rules and regulations surrounding this issue. However, the other aspect, quantity, is as essential as the pricing of material. In order for a valuation to be correct, the quantity on hand needs to be accurate (Friberg et al., 2006).

The FIFO and WAP inventory methods can result in different cost of goods sold in naira amount and they affect the figure of closing inventory. These differences are important because they affect the manufacturing company's financial statements. The cost of goods sold is usually one of the large assets on their balance sheets.

As a result of the issues raised above, there is need for a superiority test between the two commonly used inventory valuation methods that are recommended by IFRS and their influence on the financial reporting in the Nigerian textiles industry.

\subsection{Objectives of the study}

The main objective of this study is to examine the inventory and reporting practices in the Nigeria textile industry, testing the superiority between FIFO and WAP stock valuation methods in the industry. The specific objectives are:

1. To ascertain the common method being used by the Nigerian textile firms in valuing of their inventory.

2. To find out the method preferred between FIFO and WAP by the firms in the industry and why.

3. To provide acceptable basis of valuing inventory for the determination of cost of closing stock figure and cost of goods produced for sale.

\subsection{Hypotheses of the Study}

In order to assist in achieving the objective of the study, the following null hypotheses are formulated in order to provide for statistical test:

$\mathrm{H}_{01}$ : Nigerian Textile firms does not use either of FIFO or WAP method in valuing their inventory.

$\mathrm{H}_{02}$ : There is no acceptable basis in valuing inventory for the determination of cost of closing stock figure and cost of goods produced for sale in the Nigerian Textile Companies.

$\mathrm{H}_{3}$ : The majority of the firms in the Nigerian Textile Industry does not prefer FIFO to WAP as a method of Inventory valuation.

\subsection{Significance of the study}

The study will enlighten individuals and organizations on the appropriate valuation and reporting practices of inventory. To the global economy, the paper will enhance adequate contribution to organization(s) that will be making use of the recommendations of the recent write up, in terms of effective inventory valuation. The research will also assist organizations that use inventory to evaluate the role played by inventory management system in safeguarding against fraud, waste, inefficiency and inaccuracy and help in securing compliance with company's policies and evaluating the level of performance in all areas or divisions of the companies.

\subsection{Scope of the Study}

This research work would be based on inventory valuation and reporting practices in Textile Industry in Nigeria: superiority test between FIFO and WAP, evidence from selected Textile companies within North west political zone of Nigeria. The focus of the study was on inventory practice and reporting and testing the superiority between the FIFO and WAP methods as it applies to the Nigerian Textile Industry. 


\section{Review of Related Literature}

\subsection{Conceptual Framework}

Stocks (otherwise referred to as Inventories) are items of value held for use or sale by an enterprise and usually comprise, raw materials and supplies used in production, work-in-progress and finished goods. The statement also stressed that, Stocks include those finished goods and livestock awaiting sale, work-in-progress, raw materials and supplies to be consumed in the production of goods or the rendering of services (Adeniji, 2009).

The American Institute of Accountants, as cited in Yusuf (2003), defined the term inventory as "the aggregate of those items of tangible property which (1) are held for sale in the ordinary course of business, (2) are in process of production for such sale or (3) are to be available for 'sale'. In Nigeria, inventory is usually referred to as stock-in-trade or work-in-progress. Stock may consist of (i) Raw materials and supplies to be consumed in production (ii) work-in-progress, or partly manufactured goods and (iii) Finished stock or goods ready for sale.

Inventory valuation using a periodic inventory tracking system is an important part of determining the cost of goods sold for a business. Businesses can choose which method to use when preparing their financial statements and each will have their own effects on the income statement and the balance sheet. There are two different tracking methods that a business can use: the perpetual inventory system and the periodic inventory system (Boardman, 2010). Under a perpetual inventory system, inventory items are accounted for when they are purchased and when they are sold. Perpetual inventory systems keep a running track of units and dollar costs to provide up to the minute inventory valuations (Boardman, 2010).

According to Akin (1995), as cited in Lawal (1998), Inventory management is the process of ensuring that the stock held by the organization is supplied to units that require the items, bearing in mind the factors of cost, time, location, quantity and quality. Lawal (1998) stresses that inventory management rest on the right material in the right quantity at right time and place, with the right cost.

Olowe (2009) opined that inventory management is concerned with efficient of stocks to achieve an optimum inventory in the firm's working capital. Kurfi (2003) also stressed that, inventory form the linked between production and sales of product, it represent the major current asset investment in most manufacturing firms. A proper stocking process is required to ensure that items are available whenever needed.

(1999) cited in Sagagi (2005), in general, the Nigerian textile industry is divided into spinners and non-spinners. Most of the spinners are also weavers and together account for some $80 \%$ of the available weaving capacity. Two- third of the spinners are located outside Lagos, they are mostly found in Kano, Kaduna and one each in Gusau, Funtua, llorin, Aba, Onitsha and Ado Ekiti.

\subsection{Material pricing Issues}

According to The Institute of Cost Accountants of India (2009), one of the important aspects of issue control is of pricing of the issues. Material is issued to production and it is necessary to find out the consumption value of the material. However the question is that at what price the issue is to be charged. Obviously the answer is that the issues should be priced at the same price at which they are purchased.

\subsection{Valuation methods of inventory according to IFRS and US GAAP}

The item 'inventory' can be defined according to International Financial Reporting Standard (IFRS) as assets; held for sale in the ordinary course of business; used in the process of production for sales, and existing in the form of materials or supplies to be consumed in the production process or in rendering of services. Inventory owned by a manufacturing company typically include: Raw materials (RM), Work in progress (WIP) and finished goods. According to Epstein \& Jermakowicz (2010) cited in Lexell and Lindstedt (2010), the valuation methods of inventories are regulated by both IASB and FASB. Under IASB,

'IAS 2 - Inventories' is regulating FIFO as an allowed inventory method. LIFO is regulated in the 'Internal Revenue Code, Section 472' in the United States, while FIFO is allowed under both SAS and IFRS (IAS) 2, 'Inventories'. When measuring the cost of inventory IFRS provides that, an entity can elect to use one of three methods, FIFO, WAP, or SI. IFRS prohibits the use of the LIFO approach. US GAAP on the other hand allows LIFO. IFRS requires that inventories be reported above cost at companies operating in certain specialized industries (eg Agriculture, mining and broker dealer). US GAAP: Inventories rarely will be reported above cost (exceptions are extremely limited). 


\subsection{First-In, First-Out (FIFO) inventory valuation method}

FIFO is, according to Comiskey et al. (2008) as cited in (ibid), a valuation method of inventories allowed under both IFRS and US GAAP. Within FIFO, companies account for selling the products in their inventory that were purchased first, which means that the COGS is small assuming that prices increase. The inventories on the other hand, are larger compared to LIFO. Further explain that with decreased COGS; the net income will be higher, which will generate higher income tax provision than if LIFO was used. Therefore, the COGS will be calculated as low during inflations with the earliest purchased inventories valuated in COGS. The last purchased items are valued in the inventory and generate higher valuation of inventory (Comiskey et al., 2008; Bragg, 2004 in Ibid). During periods of decreasing prices, FIFO would lead to higher expenses since the earliest bought products cost more and are valued in COGS.

\subsection{Last-In, First-Out (LIFO) inventory valuation method}

LIFO is an inventory valuation method in accounting, which is acceptable according to US GAAP but not by IFRS. According to Comiskey et al. (2008) cited in Lexell and Lindstedt (2010), LIFO is not allowed by IFRS since companies using LIFO show a lower income when prices increase. Hence, LIFO shows a lower net income than American companies using FIFO and consequently smaller income tax provision in the United States. Until 1930, American companies used LIFO even though FIFO was the acceptable accounting standard. The applicability of LIFO was questioned since the tax payment differed between the two methods.

According to Hoffman and McKenzie (2009a) as cited in Lexell and Lindstedt (2010), in 1930, a verdict from the Supreme Court in United States stated that LIFO was not accepted as an accounting valuation method of inventories. However, this was changed in the Revenue Act of 1939 which allowed LIFO in accounting, but only if it was used for financial reporting as well. Professionals within accounting are separated between those who believe that LIFO does not show the real economic value of a company's inventory, and those who argue that LIFO is the best valuation method for inventories. An important matter is the comparability between companies that use LIFO and the ones that do not. Hoffman \& McKenzie (2009a) cited in Lexell and Lindstedt (2010), in 1984, AICPA proposed a rule regarding the use of LIFO as long as the American companies showed the difference between the reported LIFO and FIFO. Investors have to be able to compare the two methods in a convenient way.

Consequently, companies that use the LIFO method are required to give the information of their inventory valuation in accordance to the FIFO method as well in their financial statements.

\section{FIFO Vs WAP}

According to Accounting Continuing Professional Education (2012), FIFO is a contraction of the term "first in, first out," and means that the goods first added to inventory are assumed to be the first goods removed from inventory for sale. WAP is a contraction of the term "Weighted Average Price," under this method; it is assumed that the cost of inventory is based on the average cost of the goods available for sale during the period. The average cost is computed by dividing the total cost or goods available sale by the total units available for sale. This gives a weighted average unit cost that is applied to the units in the ending inventory (Rajaskara and Lalitha, 2011). Both terms are accounting concepts used to value the cost of goods sold and ending inventory.

\begin{tabular}{||l||l||}
\hline \hline Issue & FIFO Method \\
\hline \hline Materials flow & In most businesses, the actual flow of materials follows FIFO, which makes this a logical choice. \\
\hline \hline Inflation & $\begin{array}{l}\text { If costs are increasing, the first items sold are the least expensive, so your cost of goods sold decreases, } \\
\text { you report more profits, and therefore pay a larger amount of income taxes in the near term. }\end{array}$ \\
\hline \hline Deflation & $\begin{array}{l}\text { If costs are decreasing, the first items sold are the most expensive, so your cost of goods sold increases, } \\
\text { you report fewer profits, and therefore pay a smaller amount of income taxes in the near term. }\end{array}$ \\
\hline \hline Financialreporting & There are no GAAP or IFRS restrictins on the use of FIFO in reporting financial results. \\
\hline \hline Record keeping & $\begin{array}{l}\text { There are usually fewer inventory layers to track in a FIFO system, since the oldest layers are continually } \\
\text { used up. This reduces record keeping. }\end{array}$ \\
\hline \hline $\begin{array}{l}\text { Reporting } \\
\text { fluctuations }\end{array}$ & $\begin{array}{l}\text { Since there are few inventory layers, and those layers reflect recent pricing, there are rarely any unusual } \\
\text { spikes or drops in the cost of goods sold that are caused by accessing old inventory layers. }\end{array}$ \\
\hline \hline
\end{tabular}

Source: Accounting Continuing Professional Education (CPE), (2012). 
WAP, is similar to the simple average price, except that whenever a new purchase is made, the costs is added to the value of the balance in hand and the total units purchased is also added to the units in stock. Thus, the new weighted average price will be determined by dividing total cost of the total material available by the total units in stocks. In the words of Abdullahi, (2011), when compared with other methods of material pricing, it is quite different from the others explained above because for every receipt of material, there is a need to arrive at a new average price.

The followings are some of the sterling advantages of WAP;

(i) It evens out fluctuations in the price of materials.

(ii) The use of the method is not limited to materials with stable prices.

(iii) It presents a fair indication of stock values.

Meanwhile, Abdullahi (2011), identified some disadvantages of WAP as follows; (a) it is difficult to operate, (b) ruling prices usually run to a number of decimal places, (c) issues to production and other uses may not reflect current economic values.

\subsection{Review of Empirical Studies}

The majority of companies use the FIFO inventory valuation method, while some opt to use the LIFO inventory valuation or the weighted average valuation method. There is no "correct" method; however, Heintz and Parry (2008) opined that FIFO can increase income shown on the income statements when older inventory costs are lower than newer inventory costs; cost of goods sold (COGAS) is lower which in turn increase gross income. They further stated that to change from the LIFO method to the FIFO method typically increases inventory and income in the period for which the accounting adjustment is made.

While using the WAP approach, both inventory and the cost of goods sold are based on the average cost of all units bought during a specific period. The WAP method has a different impact on the income statement compared to FIFO and LIFO (Invetopedia 2013).

According to Rajasekaran and Lalitha (2011), under WAP method, no particular flow of goods (either first or last) is recognized. Costs are to be assigned to cost of goods sold as well as goods in hand. The weighted average unit is calculated by dividing the total cost of similar units in a period by the related number of unitsIn a nutshell, inventory is a current asset. It constitutes a major part in financial statements of trading and more especially manufacturing concerns. In the words of Rajasekaran and Lalitha (2011), after cash and receivables, this plays an important role. They further stressed that the term inventory refers to the stock pile of the products a firm is offering for sale and the components that make up the product. It is a well-known fact that inventories have their own effect on the liquidity of enterprises. Therefore, the correct position of a firm can be determined only if the inventories are valued correctly.

Inventory emerges in various forms which may include stock of raw materials, sub-assemblies, semi-completed goods (work in progress), finished goods and consumables depending on the type of enterprise (Juul,2002; Waters, 2003; Garrison and Noreen, 2003) as cited in Haribhai-Pitamber and Dhurup (2014). In their recent research HaribhaiPitamber and Dhurup (2014) examined adherence to inventory control and valuation system among retail SMEs, using questionnaire administered to selected respondent using simple random sampling technique. The questionnaire comprised questions based on inventory control and valuation procedures, with closed-ended questions and likert scales. The results confirm that inventory methods have a positive association with inventory valuation methods and records. Therefore, this very research adopted the same methodology to examine the inventory valuation and reporting practices in the Nigerian Textile Industry.

\section{Methodology}

The survey design was adopted for the purpose of this study. The population of this study is made up of all eight quoted and unquoted Textile Companies in Nigeria. The method of sampling that was employed in obtaining required data is random sampling method. This calls for random selection of respondents within the target population for the determination of sample size. Sample size of one hundred and fifty (150) respondents was drawn from the categories of the population.

The required data for this study is primary; however secondary data was also used to support the primary data and also to provide for literature needed.

One hundred and fifty (150) copies of the questionnaire were administered to the selected respondents. Descriptive method of statistical data analysis is used because of the nature of objectives of the study. 


\section{Data Presentation and Analysis}

One hundred and eighteen (118) questionnaires were retrieved from the total of 150 distributed. This figure represents about 79 percent which is a good representation. chi-square statistical technique result was also used to support the result of descriptive. The result came after the descriptive statistics result.

\subsection{Discussion of Findings,}

Internal consistency test of the questionnaire was carried out using SPSS version 16 with a Cronbach's Alpha coefficient result of less than .70. With this result, reliability test of questionnaire has failed. However, the result was reviewed and we found that the less than .70 was due to few items in the questionnaire and numbers of respondents. This however, led us to conduct the mean inter-item correlation test. The result of this second test was within the range of .2 and .4 to confirm the reliability of the questionnaire as recommended by Briggs and Check (1986).

Table 4.3.1. Descriptive Statistics

\begin{tabular}{|c|c|c|c|c|c|}
\hline & $\mathrm{N}$ & Minimum & Maximum & Mean & Std. Deviation \\
\hline InvVal1 & 118 & 2 & 5 & 4.11 & .845 \\
InvVal2 & 118 & 2 & 5 & 4.05 & .895 \\
InvVal3 & 118 & 1 & 3 & 1.80 & .812 \\
Inval4 & 118 & 2 & 5 & 4.08 & .812 \\
InvVal5 & 118 & 1 & 3 & 1.46 & .517 \\
Inval6 & 118 & 2 & 5 & 4.06 & .809 \\
InvVal7 & 118 & 1 & 5 & 3.73 & 1.305 \\
InvVal8 & 118 & 1 & 5 & 3.81 & .989 \\
Inval9 & 118 & 1 & 5 & 3.95 & 1.069 \\
InvVal10 & 118 & 1 & 5 & 4.04 & .928 \\
InvVal11 & 118 & 1 & 5 & 1.81 & .896 \\
InvVal12 & 118 & 1 & 4 & 1.92 & .764 \\
InvVal13 & 118 & 1 & 4 & 1.83 & .850 \\
InvVal14 & 118 & 1 & 4 & 1.75 & .776 \\
InvVal15 & 118 & 2 & 5 & 4.24 & .736 \\
InvVal16 & 118 & 1 & 3 & 1.79 & .783 \\
Valid N (listwise) & 118 & & & & \\
\hline
\end{tabular}

Source: SPSS Version 16 outputs

The respondents to items 2 and 3 strongly agree that they know and understand both FIFO and WAP methods of inventory and how they operate. This suggests that there is no marginalization of the two methods of inventory among the respondents since they have the freedom to state their mind; they are not under pressure. They stand a chance to defend each method according to their choice that is based on practice.

Item 4 in the questionnaire has a high score mean of 4.08 while item 5 recorded a score of only 1.46 . This is a score that is far less than the average mean of 3 . The score of 4.08 under FIFO means that majority of the firms in textile industry adopt FIFO method of inventory valuation. This comparative result is not abnormal as one of the results is expected to have a higher mean score while the other should have a less score or even zero. This because it is not always possible for a firm to adopt two methods of inventory valuation at same time, where they do it will be immaterial. The results of item 4 and 5 therefore reflect the method in practice. In this study, there are very few firms within the industry that practice both methods hence the results deviate as they are.

WAP with 1.46 indicates that some firms practice more than one method of inventory valuation; in this case FIFO and WAP. This result support the literature (Abdullahi, 2011) that FIFO method is always better than other methods of valuing inventory hence it is recommended for adoption (SAS No. 4 and IFRS, 2011) by firms.

Referring to our null hypothesis one, which states that Nigerian Textile firms do not use either of FIFO or WAP method in valuing their inventory, it is clear that the above results will stand to test it. The expected average score from the 5-point Likert scale questionnaire is 3; any result less than this figure has fail the test while any mean score higher than this average reflect agreement. The result of 4.08 means very strong agreement to the adoption and implementing 
FIFO method of inventory valuation in the firms that constitutes the textile industry. This FIFO and WAP results have also achieved the first objective of this study.

Items 6 to 10 are on the characteristics of FIFO and why the method should be preferred to WAP. The means scores of the five items are: $4.06,3.73,3.81,3.95$ and 4.04 . The total average score is 3.92 , a point that is far above expected average of 3 . This is to state that all the scores in this category is significant in the sense that all of them fall into the agreement column. The first item on FIFO characteristics which states that it is simple to understand and operate has a mean score of 4.06; this is far beyond average of 3 from 5-point Likert scale. The second question which is equivalent to item 7, stresses that under FIFO, profit is stable as materials costs are charged on actual cost of acquisition. The statistical calculation of the responses has a mean score of 3.73 , also a point that is higher than the average of 3 . Item 8 from the statistical out is 3.81 with questionnaire content that FIFO method of inventory valuation produce better result in case of falling prices of materials. This is also in agreement with the opinion of Adeniji (2009). In the same vein item 9 has a mean score of 3.95. The respondents to the questionnaire have agreed to the fact that FIFO method report closing value of inventory in representative manner in the financial statements. This result is of the same view with the study of Lere (1986). The final item 10 states that FIFO method if adopted matches revenues against the cost of inventory, hence consistent with historical cost method. The descriptive statistics show a mean score of 4.04, indication high rank agreement with the item. This result is in disagreement with the study of Cooper and Kaplan (1988).

Items 11 to 14 are the comparative characteristics of WAP over FIFO and why the method should prevail over FIFO method both in theory and practice but unfortunately all the results came out unfavourable. The descriptive statistics results from these items are: 1.81, 1.92, 1.83 and 1.75; they are all very low compare with the scores both in the FIFO and expected average mean score of 3 . In a single sentence it can be inferred that WAP method of inventory valuation is acceptable when it is compared with FIFO method both in theory and practice.

The first item indicated that the method is better off when prices fluctuate while the second item shows that the WAP approach is a fair indication of inventory valuation. The items are in accordance with the assumptions of literatures (Dandago and Tijjani (2005) and ACCA (2005) but unfortunately these are at variance from the responses obtained from the practice in firms within the textile industry in Nigeria. From the descriptive results above, the scores are 1.81 and 1.91 far below the average score of 3 . In the same vein, items 13 and 14 which state that value of inventory will be realistically represented in the financial statements and that in practice WAP is preferred to FIFO method of inventory respectively have weak results. The scores from descriptive statistics are 1.83 and 1.75 respectively.

Hypothesis two which states that there is no acceptable basis in valuing inventory for the determination of closing inventory figure and cost of goods produced for sale in the Nigerian textile firms can also be tested after comparing items 6 to 10 and 11 to 14 in the questionnaire. The average scores from FIFO method of inventory is 3.9 while WAP stands at 1.8. With these results, the hypothesis two will not be accepted because majority of the firms in the textile industry have accepted and adopted FIFO method of inventory valuation.

These results will also be used for testing the third null hypothesis which states that the majority of the firms in the Nigerian textile industry do not prefer FIFO to WAP as a method of Inventory valuation. With FIFO scoring 3.9 over the average determinant of 3 and WAP with the average score of 1.8 clearly shows that FIFO method is better and highly prefer and acceptable to WAP in terms of inventory valuation for any useful purpose in the industry. Items 15 and 16 with the mean statistics of 4.24 and 1.79 respectively are complementary and support to items 6 to 14 in the questionnaire, and there results are in agreement with the mean scores already discussed.

\subsection{Summary of Findings}

It can be inferred that there is no one single method of valuing inventory which is accepted as accurate in determination of cost of inventory in the Nigeria Textile Industry. There is freedom by individual firm to adopt any suitable method of its choice. Moreover, whichever method a firm chooses is dependent on the superiority of that particular method to other valuation methods. Furthermore, for the firms in the industry to adopt a particular method which suits their peculiarity and conformity with available standard and regulations, such chosen method must certainly be superior to any other, hence FIFO is superior to WAP method.

In the Nigerian Textile Industry, the actual flow of materials follows FIFO method, owing to this fact, most firms preferred and regarded FIFO as superior to WAP and others, that is in addition to the fact that the FIFO method matches revenues against the initial cost of inventory, hence consistent with historical cost method, and giving the fact that most firms adopt historical cost concept, as basic underlining assumption in preparation of their financial statements, hence, the preference for the FIFO method, and by extension its superiority to WAP and other methods of valuation. 


\section{Summary, Conclusion and Recommendations}

The main aim of this study is to examine the inventory valuation practice and Reporting in the Nigeria Textile Industry, testing the superiority between FIFO and WAP stock valuation methods in the industry. It is crucial for management and other operators of inventory activities to analyze and understand how inventory is valued since there are many methods of pricing for whatever purpose. The following are the summary of the major findings of the study

i. It was discovered during the cause of the study that there is no one single specific method of valuing inventory which is accepted as accurate in determination of cost of inventory in the Nigerian Textiles Industry, therefore, individual firms adopt any suitable method of its choice; as such, most firms choose FIFO method.

ii. Another discovery is that once a firm/ company has adopted or chosen a specific method of valuation from the beginning of its operation, it hardly changes to another one. Also FIFO method is discovered to be easier to apply than WAP and it (FIFO) gives a more realistic cost of closing stock.

iii. The study showed that as a result of WAP matching revenue against the average cost of inventory i.e the average of historical and market costs, issues to production and other uses may not reflect current economic values.

iv. It revealed that actual flow of material follows FIFO method, and also FIFO matches revenue against the initial cost of inventory, hence consistent with historical cost method.

\subsection{Conclusion}

This research has been a great success as all the hypotheses developed for the purpose were established. The FIFO and WAP inventory methods can result in different cost of goods sold in naira amount and they affect the closing inventory in naira amounts. These differences are important because they affect the manufacturing company's financial statements. It was established that FIFO method gives a more realistic cost of closing stock as such more superior to WAP method.

\subsection{Recommendations}

Based on the findings and conclusion of the study, the following recommendations are suggested:

1. Given the peculiarity of the Nigerian Textiles Industry, all the firms/ companies should be compelled by law to adopt only FIFO method in valuing and reporting their inventory, because it gives a more realistic cost of closing stock.

2. Most firms in the Nigerian Textiles Industry already adopt FIFO method, therefore for consistency and uniformity all firms within the Industry should be required to value and report their inventory using FIFO method.

3. For equity and fairness on tax issues to both the firms and the Government, FIFO method is most recommended for the Nigerian Textiles Industry, because it matches revenue against the initial cost of inventory and therefore, does not over-state or under-state profit of the firm.

4. Finally, the use of WAP method should be discouraged in the Nigerian Textiles Industry, because it matches revenue against the average historical and market costs, as such issues to production and other uses do not normally reflect the current economic values.

\section{References}

Adefila, J.J. (2008) Research Methodology in Behavioural Sciences, Ibadan: loud books Publishers.

Adeniji, A.A. (2002) An Insight to: Management Accounting. Lagos:

EL TODA Publishers, $4^{\text {th }}$ Edition.

Adeniij, A.A. (2009) Cost Accounting: A managerial Approach. Lagos: EL-TODA Publishers, 4t Edition.

Boardman, T. (2010) Understanding difference between FIFO and LIFO. http://www.helium.com/items/1911702ContinuingProfessional Education (CPE) FIFO vs. LIFO Accounting. http://www.accounting tools.com/fifo-vs-lifo-accounting

Briggs, S. R. \& Check, J. M. (1986). The role of factor analysis in the developmental and evaluation of personality scale. Journal of Personality, 54, 106-48.

Cooper, R. \& Kaplan, R. S. (1988). How cost accounting distorts product costs. Management Accounting, 69 (10).

Chen, X., and Zheng, M (2012) Different inventory valuation methods based on AHP. International Journal of Accounting and Financial Management (IJAFM) Universal Research Group. 44-51 
Dandago, K.I. and Tijjani, B. (2005) Cost and Management Accounting. Kano: Gidan Dabino Publishers, $2^{\text {nd }}$ Edition.

Dopuch, N. and Pincus, M. (1988) Evidence on the choice of inventory accounting methods: LIFO vs FIFO. Journal of Accounting Research 26 (spring) 28-59

Eggleton, I.R.C., Penman, S.H, and Twombly, J.R. (1976) Accounting changes and prices: An examination of selected uncontrolled variables, Journal of Accounting Research, 66-88

Friberg, L., Nilsson, S. and Warnbring, S. (2006) Inventory Valuation- difficulties in Manufacturing Companies; what andwhy? Unpublished Master's Thesis. School of managementand Economics, Advanced Concepts in Logistics Management,Vaxjo University

Gagnon, J.M. (1967) Purchase versus pooling of interests : The search for predictor, Empirical Research in Accounting

Gama, U.G. (2010). Referencing and Bibliography in Adamu, Y.M. Mohammed, H. and Dandago, K.I., Readings in Social Science Research, Kano: Adamu Joji Publishers.

Haribhai-Pitamber, H.U. and Dhurup, M. (2014) Inventory Control and Valuation Systems among Retail SMEs in a Developing Country: An Exploratory Study. Mediterranean Journal of social sciences. MCSER Publishing, Rome- Italy.

Heintz, J.A and Parry Jr., R.W.(2008) College Accounting, USA: South-Western, 19th Edition.

Ibrahim, B. G. \& ljaiya G.T. (2000). "Introduction to Social Science Research Methods". Ilorin: SMS publisher. (1st Edition): pp.128-156.

ICAN, (2009) Study Packs on Strategy Financial Management: Professional Examination II, Lagos: VII Publishers.

ICAN, (2009) Study Packs on Costing and Quantitative Techniques: Professional Examination Intermediate, Lagos: V/I Publishers.

ICAN, (2009) Study Packs on Public Sector Accounting and Finance: Professional Examination II, Lagos: V/I Publishers.

Jenkins, N.T. and Pincus, M. (1998) LIFO versus FIFO; updatingwhat we have learned, USA: College of Business Administration, The University of Lowa.

Kirk, R. (2009) IFRS: A Quick Reference guide, UK: CIMAPublishers.

Kurfi, A.A. (2003) Principles of Financial Management, Kano:Benmark Publishers, $1^{\text {st }}$ Edition.

Lawal, M.I. (1998) Inventory Management in commercializedGovernment Parastatals. Unpublished Long Essay for PGDM,Department of Management Sciences, School of Post graduate Studies, Beyero University Kano.

Lere, J. C. (1986). Product pricing based on accounting costs. Accounting Review, LXI (2), pp 318-324.

Lexell, A and Lindstedt, K. (2010) The US Adoption towards IFRS under special Consideration of LIFO, Unpublished Master Thesis in Business Administration, Jonkoping, International Business School, Jonkoping University.

Marburger, D. (2008). Reconciling cost theory with cost accounting practices. Arkansas State University, http://ssrn.com./abstract= 1138851

Nigerian Accounting Standard Board (NASB). SAS4. Statement of Accounting Standard on Stock.

Olowe, A. (2009) Financial Management: Concepts, Financial System and Business Finance. Lagos: Brierly Jones Publishers, $2^{\text {nd }}$ Edition.

Rajasekaran, V. and Lalitha, R. (2011) Financial Accounting, India: Dorling Kindersley Pvt. Ltd.

Romeo, J. L., (2009) Analysis of the LIFO inventory valuation method during the onset of IFRS. Honors Scholar Theses.Paper79. http://digitalcommons.uconn.edu/srhonors_theses/79

Sagagi, M.S. (2005) Global Strategies of Textile Companies in Nigeria: Issues and Challenges, Bayero International Journal of Accounting Research, Vol. 2(1) PP. 138-150

The chartered institute of cost Accountants of India (2012), Cost and Management Accounting Intermediate Group II, India: Directorate of studies ICAI publishers.

Yusuf, A. (2003) Inventory Control and EOQ in Government Parastatals, unpublished Dissertation for PhD in Management,St. Clements University

Appendix

\begin{tabular}{|c|c|c|c|c|c|c|}
\hline$S / n$ & Item & SA & \begin{tabular}{|l|l|}
$A$ & \\
\end{tabular} & $U$ & D & SD \\
\hline 1 & Inventory and its cost/valuation both in issuing out to production and closing of financial year are important in our firm. & & & & & \\
\hline 2 & I understand first-in first-out (FIFO) method of inventory valuation and how it works & & & & & \\
\hline 3 & I understand weighted average price (WAP) method of inventory valuation and how it operates & & & & & \\
\hline 4 & In our company, we adopt FIFO method of inventory valuation & & & & & \\
\hline 5 & In our company, we adopt WAP method of inventory valuation & & & & & \\
\hline 6 & $\begin{array}{l}\text { FIFO method is preferred to WAP because: } \\
\text { i) Simple to understand and operate } \\
\text { ii) Profit is stable as materials costs are charged on actual cost of acquisition } \\
\text { iii) Better result in case of falling prices of materials } \\
\text { iv) Closing value of inventory is currently represented in financial statements } \\
\text { v) Matches revenues against the cost of inventory, hence consistent with historical cost method. }\end{array}$ & & & & & \\
\hline 7 & $\begin{array}{l}\text { WAP method is preferred to FIFO because: } \\
\text { i) It is better off when prices fluctuate } \\
\text { ii) Is a fair indication of inventory valuation } \\
\text { iii) Value of inventory will be realistically represented in financial statements } \\
\text { iv) In practice WAP is preferred to FIFO. }\end{array}$ & & & & & \\
\hline 8 & $\begin{array}{l}\text { In my opinion, the Accounting standards' } \\
\text { recommendation of FIFO method for inventory valuation is accurate including firms in the Nigerian Textiles Industry. }\end{array}$ & & & & & \\
\hline 9 & In my opinion, the WAP method should be superior both in theory and practice to FIFO method in the Nigerian Textiles Industry. & & & & & \\
\hline
\end{tabular}

